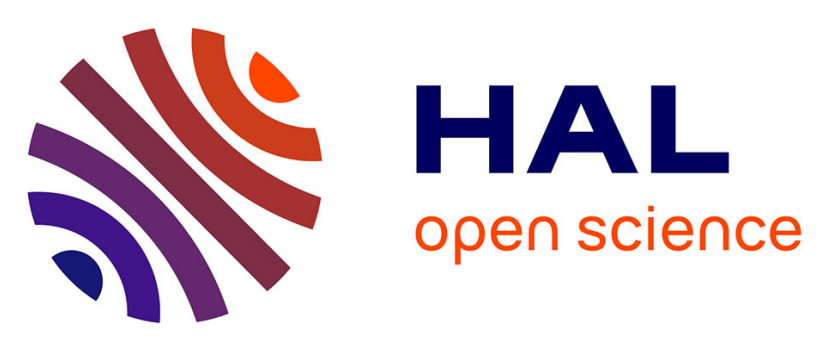

\title{
Bugs are not to be silenced: Small RNA pathways and antiviral responses in insects
}

Vanesa Mongelli, Maria-Carla P Saleh

\section{To cite this version:}

Vanesa Mongelli, Maria-Carla P Saleh. Bugs are not to be silenced: Small RNA pathways and antiviral responses in insects. Annual Review of Virology, 2016, 3 (1), pp.573-589. 10.1146/annurev-virology110615-042447 . pasteur-01957180

\section{HAL Id: pasteur-01957180 \\ https://hal-pasteur.archives-ouvertes.fr/pasteur-01957180}

Submitted on 17 Dec 2018

HAL is a multi-disciplinary open access archive for the deposit and dissemination of scientific research documents, whether they are published or not. The documents may come from teaching and research institutions in France or abroad, or from public or private research centers.
L'archive ouverte pluridisciplinaire HAL, est destinée au dépôt et à la diffusion de documents scientifiques de niveau recherche, publiés ou non, émanant des établissements d'enseignement et de recherche français ou étrangers, des laboratoires publics ou privés. 
Bugs are not to be silenced:

Small RNA pathways and antiviral responses in insects

\author{
Vanesa Mongelli and Maria-Carla Saleh*
}

Institut Pasteur, Viruses and RNA Interference Unit, Centre National de la Recherche Scientifique UMR 3569, 75724 Paris cedex 15, France

* Corresponding author: carla.saleh@pasteur.fr (M.C.S.) 


\begin{abstract}
:
As every other organism on earth, insects are infected with viruses and rely on RNA interference (RNAi) mechanisms to circumvent viral infections. A remarkable characteristic of RNAi relies on the fact that it is at the same time broadly acting, since it is triggered by double-stranded RNA molecules derived from virtually any virus, and extremely specific, because it will only target the particular viral sequence that initiated the process. Reviews covering the different facets of the RNAi antiviral immune response in insects have been published elsewhere. In this chapter, we build a frame of discussion to guide future investigation. We use this space to focus on the remaining questions and avenues of research to move the field forward, including the activity of viral suppressors of RNAi, comparative genomics, detailed maps of subcellular localization of virus replication complexes, and RNAi machinery and regulation of the antiviral RNAi response.
\end{abstract}

\title{
Keywords:
}

Insects, viruses, antiviral immunity, small RNAs, siRNAs, viral suppressors 


\section{Introduction}

Insects were among the first animals to colonize earth's ecosystems approximately 500 million years ago $(1,2)$ and now consist of the most diverse class of living organisms in terms of described species (Figure 1) (3). Insects are key participants in most terrestrial ecosystems by cycling nutrients, maintaining soil structure and fertility, pollinating plants and dispersing their seeds, controlling populations of other organisms, and serving as a food source for other organisms (4).

Insects have captured human attention since early times; indeed, the earliest objects made by humans that symbolize insects date from the Paleolithic period (10,000 years ago), and these objects depict beetles (5). For centuries, insects such as the silk worm (Bombyx mori) and the honey bee (Apis mellifera) have been protected and cherished because of their silk and honey production, while others, such as the locust (Locusta asp.), have been battled because of their devastating effects on crops. Once the capacity to act as vectors for human, livestock, and plant pathogens was established, insects became a primary research interest. In recent years, and particularly during the time we are writing this review, mosquitoes transmitting arboviruses (such as dengue, West Nile, Zika viruses) and insects transmitting agricultural diseases have become the focus of study, leaving other insect species aside. Today, few scientists have continued to study the behavior, ecology, biology, physiology, and immunity of other insects. Considering that insects constitute the most abundant taxa on earth, a return to more broad research about basic insect biology will positively influence research on all orders of life.

As every other organism on earth, insects interact with diverse pathogens. In contrast to vertebrates, insects lack an adaptive immune system and can only rely on innate immune responses to cope with these pathogens. In a very general manner, the innate immune system, which is highly conserved in all metazoans, is based on the recognition of conserved pathogen-derived molecular motifs, called pathogen-associated molecular patterns (PAMPs), by host-encoded pathogen-recognition receptors (PRRs) $(6,7)$. In insects, PAMP recognition by PRRs induces the rapid activation of Toll, Imd, and Jak-Stat signal-transduction pathways 
that lead to both humoral (e.g., secretion of antimicrobial peptides, lysozymes, or other microbe-targeting substances) and cellular (e.g., programmed cell death and autophagy) defense responses (6). These pathways were first described in insect host defense against bacteria and fungi and later shown to function in antiviral defense $(6,8,9)$. Another evolutionary conserved defense mechanism against viral infection is active in insects, the RNA interference (RNAi) mechanism, which is the subject of this review (10-12).

RNAi-based responses mediate robust antiviral activity in plants, nematodes, and insects (10, 13, 14). Antiviral RNAi is triggered in host cells following the sensing and subsequent cleavage of virus-derived double-stranded RNA (dsRNA) into small interfering RNAs (siRNAs) that guide the sequence-specific recognition of complementary viral RNA molecules, leading to their degradation and blockade of viral replication. A remarkable characteristic of this mechanism relies on the fact that it is at the same time broadly active, since it is triggered by dsRNA molecules derived from virtually any virus, and extremely specific, because it will only target the particular viral sequence that initiated the process.

Most of our knowledge on the innate immune system in insects comes from studies of the fruit fly Drosophila melanogaster and mosquitoes $(6,8)$. D. melanogaster has been the insect model of choice since early last century (15), followed by mosquitoes, which constitute the main vectors for numerous human viral pathogens throughout the world (16). Consequently, research on insect immunity is heavily focused on these two dipterans, and the RNAi field is of no exception. Reviews covering different facets of the RNAi antiviral immune response in the fruit fly and mosquitoes have been published elsewhere $(8,10,17)$. In this review, we will build a frame of discussion to advance future investigation. For several years now, research on antiviral RNAi field in insects has been centered on established conceptual frameworks. We will use this space to briefly discuss what is known and focus on the remaining questions and avenues of research to move the field forward, including the activity of viral suppressors of RNAi, comparative genomics, detailed maps of subcellular localization of virus replication complexes and RNAi machinery, and regulation of the antiviral RNAi response. 


\section{Small RNA pathways, their biological functions, and involvement in antiviral defense}

Three main small RNA-based silencing pathways are known in insects: the microRNA (miRNA), the small interfering RNA (siRNA), and the Piwi-interacting RNA (piRNA) pathways. Although they all use small RNAs (from 21 to $30 \mathrm{nts}$ ) to guide the sequencespecific recognition of target sequences by an Argonaute protein family member, these small RNAs differ in their origin, biogenesis, the nature and fate of their targets after recognition, and their biological function. We will use D. melanogaster research to briefly describe the basis of each pathway (Figure 2); for a detailed description see (18-20).

The miRNA pathway is initiated by the expression of genome-encoded miRNA gene transcripts. These primary miRNAs (pri-miRNAs) are capable of folding back on themselves to form one or more double-stranded RNA (dsRNA) stem-loop structures that trigger the pathway. pri-miRNAs are processed in the cell nucleus by a protein complex formed by Drosha and Pasha to produce the precursor miRNA (pre-miRNA), which is exported to the cytoplasm $(21,22)$. Pre-miRNAs are then further processed into 21 to 23 nucleotide (nt) small dsRNA (miRNA) duplexes by another enzymatic complex formed by Dicer-1 and Loquacious (Loqs)-PA or Loquacious-PB $(23,24)$. The miRNA duplex produced in this reaction is loaded into the Argonaute-1 (AGO1) protein-containing RNA induced silencing complex (RISC). One strand of the duplex, the miRNA*, is released from the complex and quickly degraded, forming a mature RISC containing only one small RNA strand (25). RISCs harboring miRNAs target primarily protein-coding messenger RNAs (mRNAs), producing either translational inhibition or mRNA degradation. The target recognition by the miRNA does not require perfect homology. The miRNA pathway is active in both somatic and germline tissues.

The siRNA pathway can be triggered in cells either by endogenous or exogenous dsRNA molecules. Endogenous dsRNA molecules are produced from long genomic transcripts capable of forming extensive fold-back structures or double-stranded regions generated by intermolecular hybridization of overlapped transcripts $(26,27)$. Exogenous dsRNA molecules can be derived from any environmental source, such as viral double-stranded RNA (vdsRNA) 
molecules. In the siRNA pathway, dsRNA is recognized and processed in the cytoplasm by Dicer-2 into 21 nt long small interfering RNA (siRNA) duplexes harboring two-nucleotide 3' overhangs (22). After being diced, siRNA duplexes are loaded into the Argonaute-2 containing RISC. Biogenesis and loading of siRNA duplexes into RISC requires the activity of Loqs and R2D2 as Dicer-2 cofactors. The Loqs-PD isoform and R2D2 are required in the production of siRNAs derived from endogenous dsRNAs triggers, while R2D2 is primarily recruited in the production of virus-derived siRNAs (vsiRNAs) $(28,29)$. Once loaded into the RISC, one strand of the siRNA duplex, termed the passenger strand, is eliminated from the RISC. The single-stranded vsiRNA that remains in the RISC, termed the guide strand, is then 2'-O-methylated at its 3' terminal nucleotide by the RNA methyltransferase DmHen1 (30, 31), resulting in a mature, active RISC. Sequence-specific recognition mediated by the retained siRNA guide strand, which requires complete complementarity, will then induce target RNA cleavage via the slicing activity of AGO2. While endo-siRNA targets are mostly transposons and protein-coding mRNAs, vsiRNAs recognize virus-derived sequences. As with the miRNA pathway, the siRNA pathway is ubiquitously expressed.

Molecules initiating the piRNA pathway are single-stranded RNA (ssRNA) precursors transcribed from chromosomal loci that mostly consist of remnants of transposable elements (TEs) sequences, called piRNA clusters (32). Biogenesis of piRNAs involves two steps, primary processing and secondary amplification. Production of piRNAs is Dicer independent and mainly relies on the activity of PIWI proteins, a subclass of the Argonaute family (33). Primary piRNAs are processed from ssRNA transcripts derived from piRNA clusters. Zucchini endonuclease cleaves primary piRNA precursors and generates the 5' end of mature piRNAs (34-36). The cleaved precursor is loaded into Piwi or Aubergine proteins (Piwi or Aub) and then trimmed by an unknown nuclease to reach its final length. After trimming, piRNAs undergo a final $3^{\prime}$ end $2^{\prime}$-O-methyl nucleotide modification catalyzed by 
DmHen1 $(30,31)$ to yield mature piRNAs. Primary piRNAs harbor a $5^{\prime}$ uridine bias (U1)

(37). Cleavage of the complementary active transposon RNA by primary piRNAs loaded into Aub proteins initiates the second round of biogenesis, which leads to the production of secondary piRNAs that are loaded in Argonaute-3 protein (Ago3). During this ping-pong or amplification cycle, Aub and Ago3 proteins loaded with secondary piRNAs mediate the cleavage of complementary RNA, generating new secondary piRNAs identical in sequence to the piRNA that initiated the cycle. The complementary secondary piRNAs usually have a 10 nt overlap and contain an adenine at position 10 (A10) (38). Most data indicate that the piRNA pathway is mainly active in germline tissues where it acts as a genome guardian by cleaving RNAs or transcriptionally silencing TEs.

Until recently, only the siRNA pathway was known to contribute to the antiviral response through the production of viRNAs. However, virus-derived small RNAs with piRNA features were found by next generation sequencing (NGS) in Aedes mosquitoes and mosquito cell lines infected by arboviruses (39-44). These descriptive studies were followed by direct functional analyses demonstrating that: (i) depletion of Piwi4 protein enhances replication of Semliki Forest virus (SFV, (+)RNA, Togaviridae) without interfering with vpiRNA production in Aag2 cells (45) and (ii) both Piwi5 and Ago3 are required for Sindbis virus (SINV, (+)RNA, Togaviridae) derived piRNA biogenesis in the same cell line (46). Nevertheless, functional in vivo data remain scarce, and more work needs to be done to fully understand to what extent the piRNA pathway contributes to antiviral defenses as a general mechanism, not only in mosquitoes during arboviral infections, but also in the context of other insect-virus interactions. Interestingly, unpublished studies from our laboratory show that virus-derived piRNAs are not produced by Drosophila melanogaster and, therefore, the piRNA pathway does not appear to be required for antiviral defense in this organism.

Insect miRNAs are involved in the regulation of diverse biological processes, including 
metabolism, development, differentiation, apoptosis, and innate immune responses (47). Viral infections can alter regulation of host miRNAs that can either promote or interfere with viral infection by influencing the expression of host immune response genes or viral genes involved in the establishment of infection (48-52). Viral genomes can encode their own miRNAs, which function to regulate viral gene expression or manipulate the host immune response. Among the few insect virus miRNAs identified so far, most come from viruses with double-stranded DNA genomes (dsDNA), such as Heliothis virescens ascovirus (HvAV, Ascoviridae), Bombyx mori nucleopolyhedrosis virus (BmNPV), and Autographa californica nucleopolyhedrovirus (AcMNPV) (50, 51, 53, 54). Nevertheless it has been suggested that miRNA-like molecules are encoded by two flaviviruses ((+)RNA): West Nile virus (WNV) and dengue virus (DENV) $(55,56)$. While the WNV miRNA-like molecule is thought to facilitate viral replication by targeting a cellular mRNA, the DENV miRNA-like molecule is thought to regulate virus replication by targeting a viral non-structural protein sequence $(55$, 56). The role of viral and cellular miRNAs during the antiviral response remains an enigma, but it seems to constitute a key feature of an intricate host-pathogen struggle in which both virus and host miRNAs and proteins aim to control virus and host gene expression (57-59). The elucidation of such interactions requires complex and refined research that fully addresses the biological implications and consequences besides mere descriptions and miRNA annotations.

\section{Viral suppressors of RNAi, viral counter-defense}

The existence of viral proteins with the capacity to interfere with different components of the RNAi machinery, the viral suppressors of RNAi (VSRs), highlights the relevance of the RNAi antiviral defense at the center of the host-pathogen encounter. Several viral suppressors have been identified in insect viruses of (+)RNA (Nodaviridae, Dicistrioviridae, Flaviviridae, Nora viruses with unassigned family), dsRNA (Birnaviridae), and DNA (Ascoviridae, Iridoviridae) genomes (60). Curiously, viral suppressors for (-) strand RNA viruses have not been reported. Insect virus VSRs exert their action by four main mechanisms: (1) binding 
long dsRNA to prevent Dicer-2 cleavage, (2) binding siRNAs to prevent their loading into RISC, (3) direct interaction with Dicer-2 or Ago2 proteins to prevent their action, and (4) degradation of siRNAs. In some cases, one VSR protein may combine more than one of these modes of action. For a review on insect viral suppressors of RNA, see $(10,60)$.

Most VSRs have been characterized using ex-vivo systems and in tissue culture using RNAi reporter systems or recombinant viruses $(61,62)$ without considering the natural context of an infection and the role of the VSR in pathogenesis and transmission. Despite the utility of these RNAi/VSRs reporter systems, they come with important limitations. Virus proteins usually display more than one function, and their ectopic overexpression in an in vitro system designed to detect suppression might produce false-positive results. It is difficult to prove that a viral protein with a dsRNA-binding domain is or is not a VSR in these types of experiments. For example, using a reporter assay in plants, ectopically expressed double-stranded RNA binding proteins (dsRBPs) act as VSRs (63). Indeed, Escherichia coli RNase III and the $\sigma 3$ protein from mammalian orthoreovirus (MRV) expressed in plants both display VSR activity. Strikingly, E. coli RNase III is a global gene expression regulator influencing posttranscriptional control of mRNA stability or mRNA translational efficiency in bacteria (64). The MRV $\sigma 3$ protein is a multifunctional protein that serves as a virion outer-capsid protein and mediates several activities throughout the viral life cycle (65). Whether MRV $\sigma 3$ protein can be considered as a VSR in its natural biological context remains unanswered. Another limitation of studying VSRs is the host-specificity of VSR activity. For example, VP1 proteins encoded by $D$. melanogaster Nora virus (DmelNV) and D. immigrans Nora-like virus (DimmNV) act as VSRs by interacting with Ago2 and blocking target cleavage. However, DimmNV VP1 cannot act as VSR in a D. melanogaster S2 cell reporter system. DimmNV VP1 can only interact with $D$. immigrans Ago2 (66).

An interesting facet of VSRs is their potential capacity to interfere with the normal activity of small RNA pathways due to their mode of action. While the ectopic expression of VSRs in plants interferes with the miRNA pathway and leads to pleiotropic developmental defects (67, 68), analogous experiments performed using D. melanogaster demonstrate that VSRs do not 
affect global miRNA biogenesis and function (69). These results can be reconciled by the fact that plant siRNA and miRNA pathways share biogenesis factors and both vsiRNAs and miRNAs can be loaded into Ago1 (70), whereas the main factors of these pathways in flies are not commonly shared. However, only two insect VSRs were used in these studies (FHV B2 and DCV 1A); the other VSRs were derived from plant viruses. Additionally, ectopic expression of some VSRs suppresses RNAi induced by exogenous dsRNA in embryos and endogenous siRNAs in adult flies. These results suggest that while VSRs might not have a conspicuous effect on the miRNA pathway, they appear to block the endogenous siRNA pathway, a result that is further supported by other work from the same group (71). Whether VSRs interfere with small RNA pathways in a general manner requires more research on $D$. melanogaster as well as other insect species.

Of all known insect VSRs, the B2 protein of FHV has been extensively studied. Its absence during infections of adult flies causes a defect in FHV replication and accumulation of FHVderived siRNAs (72). This study was conducted using Drosophila, which is not the natural host of FHV. However, this kind of direct experimental evidence about the role of VSRs in the virus life cycle and during infection of the host are lacking for VSRs of other insect viruses. Finally, since the piRNA pathway is involved in the antiviral response, should we expect to identify VSRs of the piRNA pathway? If so, what would be the counter-defense mechanism of viruses against antiviral piRNAs?

\section{Comparative genomics: Natural variations of RNAi components through insects}

Most of what we know about the antiviral role of small RNA-based pathways comes from studies of D. melanogaster and mosquitoes. Nevertheless, other insects like honeybees ( $A$. melifera), silk worms (Bombyx mori), reed flour beetles (Tribolium castaneum), plant virus transmitting hemipteroids (aphids, whiteflies, and thrips) and other insects with economic interest are being extensively studied (73-76). The existence of RNAi in different types of 
insects has been indirectly shown by: (i) the presence of small RNA species detected by NGS and (ii) the use of RNAi as a tool to understand the role of endogenous genes or to affect the insect life cycle as a method of pest control. However, the increasing number of genome sequencing projects, with 138 insect genome sequences now available (77), allows a detailed comparative genome and phylogenetic analysis of the RNAi pathway components present in different insect species. The number of gene copies for the key components of the small RNA pathways, Dicer and Argonaute family members, in some insect orders and species is shown in Table 1. This non-exhaustive list illustrates that small RNA-encoding genes differ in copy number between insect species. Phylogenetic analyses of small RNA-pathway components indicate that loci encoding these molecules expanded or contracted during the course of evolution (78-80). For example, miRNA expanded in the pea aphid (Acyrthosiphon pisum), the Russian wheat aphid (Diuraphis noxia), and the housefly (Musca domestica). siRNA gene expansions are found in locust (Locusta migratoria), the Russian wheat aphid, the red flour beetle (Tribolium castaneum), the parasitoid wasp (Nasonia vitripennis), diverse species of Glossinia (tsetse flies), Drosophila, and the housefly (see Figure 2 from reference (78);(81)). The piRNA pathway genes expanded both in pea and Russian wheat aphids, the parasitoid wasp, two types of ants (Camponotus floridanus and Harpegnathos saltator) and mosquitoes from Aedes, Anopheles, and Culex genera. Duplication and diversification of small RNA pathways are widely present among insects, indicating that these changes are not rare and occurred even at a species level, as shown by a study of dipteran argonautes (78) and the expansion of miRNA genes in aphids (80). 
Although gene duplications are a frequent source of novelty in host genome defense repertoires, the evolutionary fate of specific duplicates can vary. In most cases, one of the duplicated copies will be eliminated; alternatively, both copies may be retained but would acquire differentiated profiles of expression or different functions $(82,83)$. The frequent expansion of genes of the RNAi pathway is often accompanied by changes in their evolutionary rates. Some of these changes in evolutionary rate might be explained by involvement of these genes in host-pathogen interactions. Indeed, genes involved in pathogen defense evolve much faster than the rest of the genome in Drosophila. Ago-2 is a clear example of this observation, and Piwi and Aub also evolve extremely fast (84), which is thought to be attributable to adaptation to the ever-changing landscape of transposition activity in the fly. Another interesting example arises when studying the involvement of the piRNA pathway in antiviral responses in two dipterans, Drosophila and mosquitoes. While vpiRNAs are present in mosquitoes, unpublished work from our lab indicates that they are not produced during viral infections in Drosophila melanogaster. Whereas flies encode three PIWI proteins (Piwi, Aub, and Ago-3), the PIWI family is expanded to eight members (Piwi1-7 and Ago-3) in the mosquito Aedes aegypti and seven in Culex pipiens (85). It is possible that during speciation and diversification of piRNA pathway proteins, the piRNA pathway gained functions in addition to the repression of transposon activity in mosquitoes while remaining exclusively focused on the control of transposons in the fly. Alternatively, the piRNA pathway may have lost an ancestral antiviral function since the last common ancestor of flies and mosquitoes. With the advent of new sequence technology and the increasing access to metagenomic data, the field of comparative genomics and evolution 
should keep expanding knowledge about the origin, role, and diversity of RNAi genes in insects. These studies will establish a foundation for a comprehensive design of wet-lab approaches in different insect-virus combinations to unlock the secrets of antiviral RNAi in insects.

\section{Where and when? Subcellular localization of the RNAi-virus interaction}

Several independent studies indicate that the antiviral RNAi machinery is triggered by the presence of viral dsRNAs in the cell. In most cases, the source of these viral dsRNAs are viral replication intermediates (see Table 1 in (10)). Additionally, RNA viruses can be retrotranscribed into a viral DNA form by cellular reverse transcriptases. The transcription of these viral DNA forms is involved in the dsRNA biogenesis that triggers the RNAi response (see Figure 1 from (86)). However, a question surrounds this evidence: when and where in the cell does the RNAi machinery encounter the virus replication apparatus?

Viral replication is a complex and regulated process that may occur in the nucleus (dsDNA viruses and some negative-strand RNA ((-)RNA) viruses) or the cytoplasm ((+)RNA, dsRNA, some (-)RNA viruses) (Figure 3). Despite biological differences, replication of most (+)RNA viruses is associated with and localized to host-derived membranes. (+)RNA viruses form vesicular invaginations to use as an optimized environment to support viral replication and assembly. The viral dsRNA intermediate is mainly detected inside these membranous structures (87) which are connected to other membranes and open to the cytoplasm by porelike structures (88). These membranous structures or spherules (87) are derived from mitochondria during Nodaviridae infection, endosomes for Togaviridae, ER and Golgi for 
Flaviviridae, Golgi for Bunyaviridae, and autophagosome for Picornaviridae. Other virus families, such as Iridoviridae, Poxviridae, and Reoviridae form electron-dense cytoplasmic inclusions called viroplasms that house viral replication. In the case of dsRNA reoviruses, replication of the genome takes place inside viral particles. Viral dsRNA produced during viral replication is mainly localized inside viral membranous or protein structures, which may be a mechanism to protect or delay recognition of PAMPs in vertebrates $(89,90)$. The same rational can be applied to insect viruses and antiviral RNAi.

The subcellular localization of RNAi is not precisely understood, although it is proposed to occur in the cytosol. In plants and mammals, RNAi proteins are associated with endomembrane systems in the cell (91). In insects, information is scarce. R2D2 and Dicer-2 are proposed to localize in discrete cytoplasmic bodies in Drosophila cells, termed D2 bodies (92), and RISC-containing Ago1 localizes to mRNA-decay centers, suggesting that this is the final step of the RNAi pathway when target RNA will be degraded (93).

In Drosophila somatic cells from germ tissue, the primary piRNA biogenesis machinery (PIWI protein and others) localizes in perinuclear cytoplasmic structures called $\mathrm{Yb}$ bodies (Figure 3) (94). In germline cells, both primary and secondary piRNA biogenesis machinery localize in other perinuclear electron dense cytoplasmic structures known as "nuage" (20). Zucchini protein localizes to the outer membrane of mitochondria (36).

Important questions remain in considering the steps of antiviral RNAi. For example, where do Dicer and viral dsRNA meet? Is Dicer-2 $(\mathrm{a} \approx 255 \mathrm{KDa}$ protein $)$ trapped inside the spherules or the viroplasm during viral replication? Are there any signals that bring Dicer-2 to the viral replication site? If Dicer-2 is cutting viral dsRNA inside these membranous structures, how 
are siRNAs released to reach Ago2? Is it possible to find Ago2 and the RISC complex $(\approx$ 80S) in virus replication sites? Can the entire RNAi process occur inside viral replication sites and in parallel with viral replication? Once Ago2 cuts the target viral RNA, where does RNA degradation occur? Does the sliced viral RNA leave the replication site and enter an RNA decay center? Do pore-like openings serve as entry or exit portals for the RNAi machinery? The optimization of cell biology techniques in insect cells such as cell fractionation, membrane flotation, immune precipitation, electron microscopy, and electron tomography together with live-cell imaging, could be a starting point to answer these questions.

\section{Regulation of the antiviral RNAi pathway}

A general and widespread consequence of PAMP recognition by PRRs during the innate immune response in insects is the transcriptional induction of antimicrobial effector molecules $(6,95)$. Viral dsRNA molecules act as PAMPs in insects, triggering the expression of innate immune-response genes (96-98), (99). However, no such induction has been observed in insects for the antiviral RNAi response-related genes following viral infection. Of the thousands of studies of antiviral RNAi in Drosophila and mosquitoes, the subject of whether there is a basal and constant level of expression of RNAi proteins or whether expression is induced by virus infection have not been sufficiently addressed. In our hands, infection of Drosophila S2 cells with DCV or FHV does not change expression levels of Dicer-1, Dicer-2, Ago1, or Ago2. Injection or feeding of adult Drosophila with DCV does not affect the expression level of Ago2. However, there is some evidence of RNAi-related genes are induced at a transcriptional level in some experimental systems. Argonaute (Ago1, Ago2, 
Ago3, and Piwi) mRNA expression in Bombyx mori (silk worm) is induced 6 hours after infection with Bombyx mori nucleopolyhedrosis virus and is lost by 12 hours post infection (100). A study using D. melanogaster suggested that the FOXO transcription factor regulates expression of core components of the small RNA pathways in response to stress. FOXO binds to Argonaute 1 and 2 and Dicer-2 promoters and might therefore play a role in the regulation of their expression (101).

In D. melanogaster, Dicer-2 and Ago2 proteins are shared by both endogenous and exogenous siRNAs pathways. Since the endo-siRNA pathway is involved in the control of transposon expression in somatic tissues, that relationship could explain the constitutive expression of this pathway. However, the situation in the context of a viral infection is unclear. For example, would both endo- and exo-siRNA pathways share one fixed amount of RNAi effector proteins? Would the regulation rely on changes in rates of protein turnover? Could the virus be affecting a cellular function linked to the endo-siRNA pathway that we have not yet identified? If Dicer and Argonaute are constitutively expressed and not activated by the presence of the pathogen, is it possible that their antiviral role is secondary?

\section{Conclusion}

New research is starting to shed light on the diversity of mechanisms of antiviral defense in insects. These studies point to the uniqueness of each natural pathosystem (i.e., natural insectvirus system) to understand the contribution of antiviral RNAi in each case and show that, in some cases, the use of model systems may not have yielded generalizable concepts. Although time-consuming, the contribution of the RNAi pathway in the antiviral response as well as the 
interactions of RNAi with other immune pathways should be established for each individual pathogen-insect combination. This understanding will illuminate fundamental concepts in biology, clarify age-old unexplained observations, and open the door to new views, concepts, and theories about pathogen-host relationships.

\section{Acknowledgements:}

We thank members of the Saleh lab for fruitful discussions, Marco Vignuzzi and Ronald van Rij for critical review of the manuscript. This work was supported by the European Research Council (FP7/2007-2013 ERC StG 242703 and FP7/2013-2019 ERC CoG 615220) and the French Government's Investissement d'Avenir Program, Laboratoire d'Excellence "Integrative Biology of Emerging Infectious Diseases" (grant n ANR-10-LABX-62-IBEID) to M.C.S..

\section{References:}

1. Misof B, Liu S, Meusemann K, Peters RS, Donath A, et al. 2014. Phylogenomics resolves the timing and pattern of insect evolution. Science 346: 763-7

2. Tong KJ, Duchene S, Ho SY, Lo N. 2015. INSECT PHYLOGENOMICS. Comment on "Phylogenomics resolves the timing and pattern of insect evolution". Science 349: 487

3. Roskov Y, Abucay L, Orrell T, Nicolson D, Flann C, Bailly N, P. K, Bourgoin T, DeWalt RE, Decock W, De Wever A. 2016. Species 2000 \& ITIS Catalogue of Life. Leiden, the Netherlands: Naturalis

4. Scudder GGE. 2009. The Importance of Insects. In Insect Biodiversity: Science and Society, ed. RG Foottit, PH Adler: Wiley-Blackwell

5. Belles X. 1997. Los insectos y el hombre.

6. Buchon N, Silverman N, Cherry S. 2014. Immunity in Drosophila melanogaster--from microbial recognition to whole-organism physiology. Nat Rev Immunol 14: 796-810

7. Lemaitre B, Hoffmann J. 2007. The host defense of Drosophila melanogaster. Annu Rev Immunol 25: 697-743 
8. Cheng G, Liu Y, Wang P, Xiao X. 2016. Mosquito Defense Strategies against Viral Infection. Trends Parasitol 32: 177-86

9. Lamiable 0, Imler JL. 2014. Induced antiviral innate immunity in Drosophila. Curr Opin Microbiol 20: 62-8

10. Gammon DB, Mello CC. 2015. RNA interference-mediated antiviral defense in insects. Curr Opin Insect Sci 8: 111-20

11. Keene KM, Foy BD, Sanchez-Vargas I, Beaty BJ, Blair CD, Olson KE. 2004. RNA interference acts as a natural antiviral response to O'nyong-nyong virus (Alphavirus; Togaviridae) infection of Anopheles gambiae. Proc Natl Acad Sci U S A 101: 17240-5

12. Li H, Li WX, Ding SW. 2002. Induction and suppression of RNA silencing by an animal virus. Science 296: 1319-21

13. Sarkies P, Miska EA. 2013. RNAi pathways in the recognition of foreign RNA: antiviral responses and host-parasite interactions in nematodes. Biochem Soc Trans 41: 876-80

14. Szittya G, Burgyan J. 2013. RNA interference-mediated intrinsic antiviral immunity in plants. Curr Top Microbiol Immunol 371: 153-81

15. Roberts DB. 2006. Drosophila melanogaster the model organism. Entomologia Experimentalis et Applicata

The Netherlands Entomological Society 121

16. WHO.

http://www.who.int/whr/1996/media centre/executive summary1/en/ index9.html.

17. Olson KE, Blair CD. 2015. Arbovirus-mosquito interactions: RNAi pathway. Curr Opin Virol 15: 119-26

18. Carthew RW, Sontheimer EJ. 2009. Origins and Mechanisms of miRNAs and siRNAs. Cell 136: 642-55

19. Ha M, Kim VN. 2014. Regulation of microRNA biogenesis. Nat Rev Mol Cell Biol 15: 509-24

20. Theron E, Dennis C, Brasset E, Vaury C. 2014. Distinct features of the piRNA pathway in somatic and germ cells: from piRNA cluster transcription to piRNA processing and amplification. Mob DNA 5: 28

21. Denli AM, Tops BB, Plasterk RH, Ketting RF, Hannon GJ. 2004. Processing of primary microRNAs by the Microprocessor complex. Nature 432: 231-5

22. Lee YS, Nakahara K, Pham JW, Kim K, He Z, Sontheimer EJ, Carthew RW. 2004. Distinct roles for Drosophila Dicer-1 and Dicer-2 in the siRNA/miRNA silencing pathways. Cell 117: 69-81

23. Forstemann K, Tomari Y, Du T, Vagin VV, Denli AM, Bratu DP, Klattenhoff C, Theurkauf WE, Zamore PD. 2005. Normal microRNA maturation and germ-line stem cell maintenance requires Loquacious, a double-stranded RNA-binding domain protein. PLoS Biol 3: e236

24. Saito K, Ishizuka A, Siomi H, Siomi MC. 2005. Processing of premicroRNAs by the Dicer-1-Loquacious complex in Drosophila cells. PLoS Biol 3: e235

25. Miyoshi K, Tsukumo H, Nagami T, Siomi H, Siomi MC. 2005. Slicer function of Drosophila Argonautes and its involvement in RISC formation. Genes Dev 19: 2837-48

26. Czech B, Malone CD, Zhou R, Stark A, Schlingeheyde C, Dus M, Perrimon N, Kellis M, Wohlschlegel JA, Sachidanandam R, Hannon GJ, Brennecke J. 
2008. An endogenous small interfering RNA pathway in Drosophila. Nature 453: 798-802

27. Okamura K, Chung WJ, Ruby JG, Guo H, Bartel DP, Lai EC. 2008. The Drosophila hairpin RNA pathway generates endogenous short interfering RNAs. Nature 453: 803-6

28. Marques JT, Wang JP, Wang X, de Oliveira KP, Gao C, Aguiar ER, Jafari N, Carthew RW. 2013. Functional specialization of the small interfering RNA pathway in response to virus infection. PLoS Pathog 9: e1003579

29. Mirkovic-Hosle M, Forstemann K. 2014. Transposon defense by endosiRNAs, piRNAs and somatic pilRNAs in Drosophila: contributions of Loqs-PD and R2D2. PLoS One 9: e84994

30. Horwich MD, Li C, Matranga C, Vagin V, Farley G, Wang P, Zamore PD. 2007. The Drosophila RNA methyltransferase, DmHen1, modifies germline piRNAs and single-stranded siRNAs in RISC. Curr Biol 17: 126572

31. Saito K, Sakaguchi Y, Suzuki T, Suzuki T, Siomi H, Siomi MC. 2007. Pimet, the Drosophila homolog of HEN1, mediates 2'-0-methylation of Piwiinteracting RNAs at their 3' ends. Genes Dev 21: 1603-8

32. Aravin AA, Hannon GJ, Brennecke J. 2007. The Piwi-piRNA pathway provides an adaptive defense in the transposon arms race. Science 318: 761-4

33. Siomi MC, Sato K, Pezic D, Aravin AA. 2011. PIWI-interacting small RNAs: the vanguard of genome defence. Nat Rev Mol Cell Biol 12: 246-58

34. Ipsaro JJ, Haase AD, Knott SR, Joshua-Tor L, Hannon GJ. 2012. The structural biochemistry of Zucchini implicates it as a nuclease in piRNA biogenesis. Nature 491: 279-83

35. Mohn F, Handler D, Brennecke J. 2015. Noncoding RNA. piRNA-guided slicing specifies transcripts for Zucchini-dependent, phased piRNA biogenesis. Science 348: 812-7

36. Nishimasu H, Ishizu H, Saito K, Fukuhara S, Kamatani MK, Bonnefond L, Matsumoto N, Nishizawa T, Nakanaga K, Aoki J, Ishitani R, Siomi H, Siomi MC, Nureki 0. 2012. Structure and function of Zucchini endoribonuclease in piRNA biogenesis. Nature 491: 284-7

37. Saito K, Nishida KM, Mori T, Kawamura Y, Miyoshi K, Nagami T, Siomi H, Siomi MC. 2006. Specific association of Piwi with rasiRNAs derived from retrotransposon and heterochromatic regions in the Drosophila genome. Genes Dev 20: 2214-22

38. Gunawardane LS, Saito K, Nishida KM, Miyoshi K, Kawamura Y, Nagami T, Siomi H, Siomi MC. 2007. A slicer-mediated mechanism for repeatassociated siRNA 5' end formation in Drosophila. Science 315: 1587-90

39. Brackney DE, Scott JC, Sagawa F, Woodward JE, Miller NA, Schilkey FD, Mudge J, Wilusz J, Olson KE, Blair CD, Ebel GD. 2010. C6/36 Aedes albopictus cells have a dysfunctional antiviral RNA interference response. PLoS Negl Trop Dis 4: e856

40. Hess AM, Prasad AN, Ptitsyn A, Ebel GD, Olson KE, Barbacioru C, Monighetti C, Campbell CL. 2011. Small RNA profiling of Dengue virusmosquito interactions implicates the PIWI RNA pathway in anti-viral defense. BMC Microbiol 11: 45 
41. Leger P, Lara E, Jagla B, Sismeiro O, Mansuroglu Z, Coppee JY, Bonnefoy E, Bouloy M. 2013. Dicer-2- and Piwi-mediated RNA interference in Rift Valley fever virus-infected mosquito cells. J Virol 87: 1631-48

42. Morazzani EM, Wiley MR, Murreddu MG, Adelman ZN, Myles KM. 2012. Production of virus-derived ping-pong-dependent piRNA-like small RNAs in the mosquito soma. PLoS Pathog 8: e1002470

43. Scott JC, Brackney DE, Campbell CL, Bondu-Hawkins V, Hjelle B, Ebel GD, Olson KE, Blair CD. 2010. Comparison of dengue virus type 2-specific small RNAs from RNA interference-competent and -incompetent mosquito cells. PLoS Negl Trop Dis 4: e848

44. Vodovar N, Bronkhorst AW, van Cleef KW, Miesen P, Blanc H, van Rij RP, Saleh MC. 2012. Arbovirus-derived piRNAs exhibit a ping-pong signature in mosquito cells. PLoS One 7: e30861

45. Schnettler E, Donald CL, Human S, Watson M, Siu RW, McFarlane M, Fazakerley JK, Kohl A, Fragkoudis R. 2013. Knockdown of piRNA pathway proteins results in enhanced Semliki Forest virus production in mosquito cells. J Gen Virol 94: 1680-9

46. Miesen P, Girardi E, van Rij RP. 2015. Distinct sets of PIWI proteins produce arbovirus and transposon-derived piRNAs in Aedes aegypti mosquito cells. Nucleic Acids Res 43: 6545-56

47. Lucas K, Raikhel AS. 2013. Insect microRNAs: biogenesis, expression profiling and biological functions. Insect Biochem Mol Biol 43: 24-38

48. Etebari K, Osei-Amo S, Blomberg SP, Asgari S. 2015. Dengue virus infection alters post-transcriptional modification of microRNAs in the mosquito vector Aedes aegypti. Sci Rep 5: 15968

49. Li JM, Zhou YR, Sun ZT, Wang X, Xie L, Chen JP. 2015. Identification and profiling of conserved and novel microRNAs in Laodelphax striatellus in response to rice black-streaked dwarf virus (RBSDV) infection. Genom Data 3: 63-9

50. Mehrabadi M, Hussain M, Asgari S. 2013. MicroRNAome of Spodoptera frugiperda cells (Sf9) and its alteration following baculovirus infection. $J$ Gen Virol 94: 1385-97

51. Singh CP, Singh J, Nagaraju J. 2012. A baculovirus-encoded MicroRNA (miRNA) suppresses its host miRNA biogenesis by regulating the exportin-5 cofactor Ran. J Virol 86: 7867-79

52. Slonchak A, Hussain M, Torres S, Asgari S, Khromykh AA. 2014. Expression of mosquito microRNA Aae-miR-2940-5p is downregulated in response to West Nile virus infection to restrict viral replication. J Virol 88: 8457-67

53. Wu YL, Wu CP, Liu CY, Hsu PW, Wu EC, Chao YC. 2011. A non-coding RNA of insect $\mathrm{HzNV}-1$ virus establishes latent viral infection through microRNA. Sci Rep 1: 60

54. Zhu M, Wang J, Deng R, Xiong P, Liang H, Wang X. 2013. A microRNA encoded by Autographa californica nucleopolyhedrovirus regulates expression of viral gene ODV-E25. J Virol 87: 13029-34

55. Hussain M, Asgari S. 2014. MicroRNA-like viral small RNA from Dengue virus 2 autoregulates its replication in mosquito cells. Proc Natl Acad Sci U $S$ A 111: 2746-51 
56. Hussain M, Torres S, Schnettler E, Funk A, Grundhoff A, Pijlman GP, Khromykh AA, Asgari S. 2012. West Nile virus encodes a microRNA-like small RNA in the 3' untranslated region which up-regulates GATA4 mRNA and facilitates virus replication in mosquito cells. Nucleic Acids Res 40: 2210-23

57. Libri V, Miesen P, van Rij RP, Buck AH. 2013. Regulation of microRNA biogenesis and turnover by animals and their viruses. Cell Mol Life Sci 70: 3525-44

58. Xie M, Steitz JA. 2014. Versatile microRNA biogenesis in animals and their viruses. RNA Biology 11: 673-81

59. Zhuo Y, Gao G, Shi JA, Zhou X, Wang X. 2013. miRNAs: biogenesis, origin and evolution, functions on virus-host interaction. Cell Physiol Biochem 32: 499-510

60. Bronkhorst AW, van Rij RP. 2014. The long and short of antiviral defense: small RNA-based immunity in insects. Curr Opin Virol 7: 19-28

61. Nayak A, Berry B, Tassetto M, Kunitomi M, Acevedo A, Deng C, Krutchinsky A, Gross J, Antoniewski C, Andino R. 2010. Cricket paralysis virus antagonizes Argonaute 2 to modulate antiviral defense in Drosophila. Nat Struct Mol Biol 17: 547-54

62. van Cleef KW, van Mierlo JT, van den Beek M, van Rij RP. 2011. Identification of viral suppressors of RNAi by a reporter assay in Drosophila S2 cell culture. Methods Mol Biol 721: 201-13

63. Lichner Z, Silhavy D, Burgyan J. 2003. Double-stranded RNA-binding proteins could suppress RNA interference-mediated antiviral defences. $J$ Gen Virol 84: 975-80

64. Dasgupta S, Fernandez L, Kameyama L, Inada T, Nakamura Y, Pappas A, Court DL. 1998. Genetic uncoupling of the dsRNA-binding and RNA cleavage activities of the Escherichia coli endoribonuclease RNase III--the effect of dsRNA binding on gene expression. Mol Microbiol 28: 629-40

65. Olland AM, Jane-Valbuena J, Schiff LA, Nibert ML, Harrison SC. 2001. Structure of the reovirus outer capsid and dsRNA-binding protein sigma3 at 1.8 A resolution. EMBO J 20: 979-89

66. van Mierlo JT, Overheul GJ, Obadia B, van Cleef KW, Webster CL, Saleh MC, Obbard DJ, van Rij RP. 2014. Novel Drosophila viruses encode hostspecific suppressors of RNAi. PLoS Pathog 10: e1004256

67. Chapman EJ, Prokhnevsky AI, Gopinath K, Dolja VV, Carrington JC. 2004. Viral RNA silencing suppressors inhibit the microRNA pathway at an intermediate step. Genes Dev 18: 1179-86

68. Zhang X, Yuan YR, Pei Y, Lin SS, Tuschl T, Patel DJ, Chua NH. 2006. Cucumber mosaic virus-encoded $2 \mathrm{~b}$ suppressor inhibits Arabidopsis Argonaute1 cleavage activity to counter plant defense. Genes Dev 20: 3255-68

69. Berry B, Deddouche S, Kirschner D, Imler JL, Antoniewski C. 2009. Viral suppressors of RNA silencing hinder exogenous and endogenous small RNA pathways in Drosophila. PLoS One 4: e5866

70. Voinnet 0. 2009. Origin, biogenesis, and activity of plant microRNAs. Cell 136: 669-87

71. Fagegaltier D, Bouge A-L, Berry B, Poisot E, Odile Sismeiro, Coppee J-Y, Theodore L, Voinnet O, Antoniewski C. 2009. The endogenous siRNA 
pathway is involved in heterochromatin formation in Drosophila. Proc Natl Acad Sci U S A vol. 106

72. Aliyari R, Wu Q, Li HW, Wang XH, Li F, Green LD, Han CS, Li WX, Ding SW. 2008. Mechanism of induction and suppression of antiviral immunity directed by virus-derived small RNAs in Drosophila. Cell Host Microbe 4: 387-97

73. Belles X. 2010. Beyond Drosophila: RNAi in vivo and functional genomics in insects. Annu Rev Entomol 55: 111-28

74. Brutscher LM, Flenniken ML. 2015. RNAi and Antiviral Defense in the Honey Bee. J Immunol Res 2015: 941897

75. Terenius O, Papanicolaou A, Garbutt JS, Eleftherianos I, Huvenne H, Kanginakudru S, Albrechtsen M, An C, Aymeric JL, Barthel A, Bebas P, Bitra K, Bravo A, Chevalier F, Collinge DP, Crava CM, de Maagd RA, Duvic B, Erlandson M, Faye I, Felfoldi G, Fujiwara H, Futahashi R, Gandhe AS, Gatehouse HS, Gatehouse LN, Giebultowicz JM, Gomez I, Grimmelikhuijzen CJ, Groot AT, Hauser F, Heckel DG, Hegedus DD, Hrycaj S, Huang L, Hull JJ, Iatrou $\mathrm{K}$, Iga $\mathrm{M}$, Kanost MR, Kotwica J, Li C, Li J, Liu J, Lundmark M, Matsumoto S, Meyering-Vos M, Millichap PJ, Monteiro A, Mrinal N, Niimi T, Nowara D, Ohnishi A, Oostra V, Ozaki K, Papakonstantinou M, Popadic A, Rajam MV, Saenko S, Simpson RM, Soberon M, Strand MR, Tomita S, Toprak U, Wang P, Wee CW, Whyard S, Zhang W, Nagaraju J, FfrenchConstant RH, Herrero S, Gordon K, Swevers L, Smagghe G. 2011. RNA interference in Lepidoptera: an overview of successful and unsuccessful studies and implications for experimental design. J Insect Physiol 57: 23145

76. Christiaens 0, Smagghe G. 2014. The challenge of RNAi-mediated control of hemipterans. Current Opinion in Insect Science 6: 15-21

77. Yin C, Shen G, Guo D, Wang S, Ma X, Xiao H, Liu J, Zhang Z, Liu Y, Zhang Y, Yu K, Huang S, Li F. 2016. InsectBase: a resource for insect genomes and transcriptomes. Nucleic Acids Res 44: D801-7

78. Lewis SH, Salmela H, Obbard DJ. 2016. Duplication and Diversification of Dipteran Argonaute Genes, and the Evolutionary Divergence of Piwi and Aubergine. Genome Biol Evol 8: 507-18

79. Lu HL, Tanguy S, Rispe C, Gauthier JP, Walsh T, Gordon K, Edwards O, Tagu D, Chang CC, Jaubert-Possamai S. 2011. Expansion of genes encoding piRNA-associated argonaute proteins in the pea aphid: diversification of expression profiles in different plastic morphs. PLoS One 6: e28051

80. Ortiz-Rivas B, Jaubert-Possamai S, Tanguy S, Gauthier JP, Tagu D, Claude R. 2012. Evolutionary study of duplications of the miRNA machinery in aphids associated with striking rate acceleration and changes in expression profiles. BMC Evol Biol 12: 216

81. Hain D, Bettencourt BR, Okamura K, Csorba T, Meyer W, Jin Z, Biggerstaff J, Siomi H, Hutvagner G, Lai EC, Welte M, Muller HA. 2010. Natural variation of the amino-terminal glutamine-rich domain in Drosophila argonaute2 is not associated with developmental defects. PLoS One 5: e15264

82. Hahn MW. 2009. Distinguishing among evolutionary models for the maintenance of gene duplicates. J Hered 100: 605-17 
83. Innan H, Kondrashov F. 2010. The evolution of gene duplications: classifying and distinguishing between models. Nat Rev Genet 11: 97-108

84. Obbard DJ, Gordon KH, Buck AH, Jiggins FM. 2009. The evolution of RNAi as a defence against viruses and transposable elements. Philos Trans $R$ Soc Lond B Biol Sci 364: 99-115

85. Campbell CL, Black WCt, Hess AM, Foy BD. 2008. Comparative genomics of small RNA regulatory pathway components in vector mosquitoes. $B M C$ Genomics 9: 425

86. Goic B, Saleh MC. 2012. Living with the enemy: viral persistent infections from a friendly viewpoint. Curr Opin Microbiol 15: 531-7

87. Ahlquist P. 2006. Parallels among positive-strand RNA viruses, reversetranscribing viruses and double-stranded RNA viruses. Nat Rev Microbiol 4: 371-82

88. Romero-Brey I, Bartenschlager R. 2014. Membranous replication factories induced by plus-strand RNA viruses. Viruses 6: 2826-57

89. Overby AK, Popov VL, Niedrig M, Weber F. 2010. Tick-borne encephalitis virus delays interferon induction and hides its double-stranded RNA in intracellular membrane vesicles. J Virol 84: 8470-83

90. Randall RE, Goodbourn S. 2008. Interferons and viruses: an interplay between induction, signalling, antiviral responses and virus countermeasures. J Gen Virol 89: 1-47

91. Kim YJ, Maizel A, Chen X. 2014. Traffic into silence: endomembranes and post-transcriptional RNA silencing. EMBO J 33: 968-80

92. Nishida KM, Miyoshi K, Ogino A, Miyoshi T, Siomi H, Siomi MC. 2013. Roles of R2D2, a cytoplasmic D2 body component, in the endogenous siRNA pathway in Drosophila. Mol Cell 49: 680-91

93. Eulalio A, Huntzinger E, Izaurralde E. 2008. GW182 interaction with Argonaute is essential for miRNA-mediated translational repression and mRNA decay. Nat Struct Mol Biol 15: 346-53

94. Murota Y, Ishizu H, Nakagawa S, Iwasaki YW, Shibata S, Kamatani MK, Saito K, Okano H, Siomi H, Siomi MC. 2014. Yb integrates piRNA intermediates and processing factors into perinuclear bodies to enhance piRISC assembly. Cell Rep 8: 103-13

95. Hoffmann JA. 2003. The immune response of Drosophila. Nature 426: 338

96. Deddouche $S$, Matt N, Budd A, Mueller S, Kemp C, Galiana-Arnoux D, Dostert C, Antoniewski C, Hoffmann JA, Imler JL. 2008. The DExD/H-box helicase Dicer-2 mediates the induction of antiviral activity in drosophila. Nat Immunol 9: 1425-32

97. Flenniken ML, Andino R. 2013. Non-specific dsRNA-mediated antiviral response in the honey bee. PLoS One 8: e77263

98. Paradkar PN, Trinidad L, Voysey R, Duchemin JB, Walker PJ. 2012. Secreted Vago restricts West Nile virus infection in Culex mosquito cells by activating the Jak-STAT pathway. Proc Natl Acad Sci U S A 109: 1891520

99. Lozano J, Gomez-Orte E, Lee HJ, Belles X. 2012. Super-induction of Dicer-2 expression by alien double-stranded RNAs: an evolutionary ancient response to viral infection? Dev Genes Evol 222: 229-35 
100. Wang GH, Jiang L, Zhu L, Cheng TC, Niu WH, Yan YF, Xia QY. 2013. Characterization of Argonaute family members in the silkworm, Bombyx mori. Insect Sci 20: 78-91

101. Spellberg MJ, Marr MT, 2nd. 2015. FOXO regulates RNA interference in Drosophila and protects from RNA virus infection. Proc Natl Acad Sci U S A 112: $14587-92$ 


\section{Figure Legends:}

\section{Figure 1: Insects rule}

The Insecta class represents $86.5 \%$ of all species described for the Animalia kingdom. Indeed, insects are among the most extensive and diverse group of life. The size of each circle is proportional to the number of species for each kingdom, including viruses.

\section{Figure 2: The elements of RNAi in Drosophila.}

(Adapted from Vodovar and Saleh, AIP 2012)

A) The miRNA pathway is initiated by the transcription of miRNA genes. Primary miRNA (pri-miRNA) transcripts are first processed by the Drosha/Pasha complex in the nucleus then exported to the cytoplasm as pre-miRNAs. There, Dcr-1 and loquacious (loqs) complete the processing and deliver the mature miRNA to AGO1-containing RISC. The miRNA* (star) is eliminated and the guide miRNA directs translational repression or cleavage of the cognate mRNA.

B) The siRNA pathway is initiated by dsRNA of viral or genomic origin which is recognised and cleaved by Dcr-2 with the help of loqs. The resulting double-stranded siRNAs are delivered to AGO2-containing RISC by Dcr-2 and R2D2. The passenger strand is eliminated and the guide siRNA directs the degradation of the target RNA via AGO2 catalytic activity.

C) The piRNA pathway is initiated when primary piRNAs are processed from single-stranded RNA precursors derived from TEs sequences, named the piRNA clusters. Zucchini endonuclease (Zuc) cleaves the primary piRNAs precursors and generates the 5 ' end of the 
mature piRNAs. The precursor is then loaded into Piwi or Aubergine (Piwi or Aub), trimmed to reach its final length and methylated by Hen1 to become mature piRNAs. Cleavage of complementary active transposon transcript by primary piRNAs loaded into Aub proteins initiates the second biogenesis round and leads to the production of secondary piRNAs that are loaded in Argonaute-3 protein (Ago-3). This amplification cycle is named ping-pong.

\section{Figure 3: RNAi, where are you?}

Subcellular localization of viral replication sites and RNAi machinery. Viral replication occurs in specialized membranous environments within host cells. The site at which the RNAi machinery encounters viral replication intermediates is unknown. 
Table 1: Number of gene copies for the key components of the small RNA pathways in some insect orders and species.

?: not known

0: not found

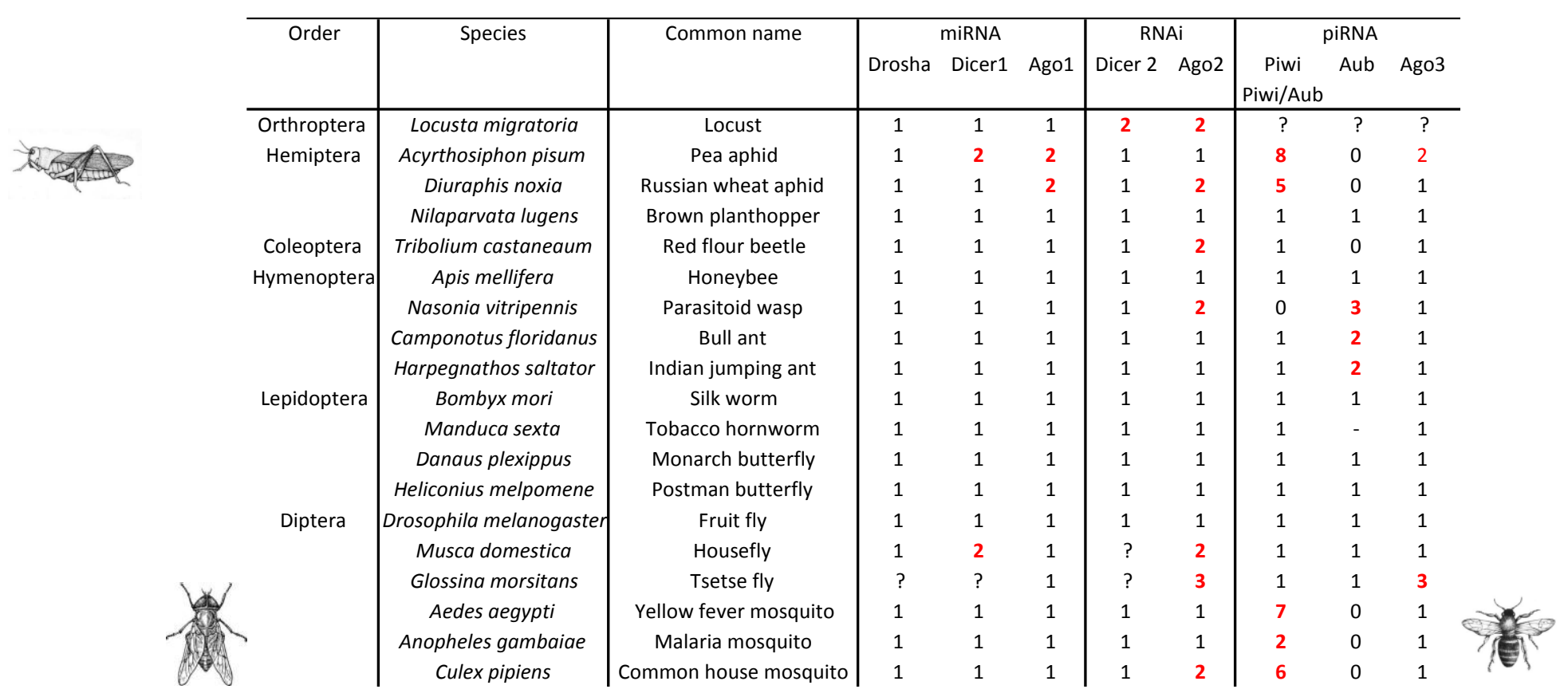

